\title{
Food intolerance
}

\section{By M. H. Lessof, Guy's Hospital Medical School, London $S E_{1}{ }_{9} R T$}

When considered as a clinical problem, adverse reactions to food have to be differentiated from various types of food aversion, as exemplified by psychogenic vomiting or by episodes of weakness and paraesthesiae due to hyperventilation. Even when the presence of intolerant reactions is confirmed by placebo-controlled challenge, in which the food is given in an unidentifiable form (in a capsule, a flavoured puree, or through a nasogastric tube), there are a number of possible explanations. The symptoms vary (Table 1 ), not only in character but also in time of onset. Where they are confined to the gastrointestinal tract they may depend on a number of causes including enzyme deficiencies (Table 2). In allergic and pseudo-allergic cases, gastrointestinal symptoms are variable but features such as asthma, eczema and urticaria are common. This classification remains tentative. In many cases, including most reactions to food additives, the mechanism is unknown.

\section{Enzyme deficiencies}

While a number of rare enzyme defects cause problems in infancy, in many parts of the world cow's milk intolerance, due to alactasia, is also seen in adults and is common. Another common enzyme defect occurs in the Far East where, because of lack of aldehyde dehydrogenase (EC 1.2.1.3), alcohol-induced facial flushing and

Table I. Gastrointestinal reactions to foods (Lessof, 1983)

Direct effects

Indirect consequences

Remote effects
Nausea, vomiting, pain, bloating, diarrhoea, constipation

Steatorrhoea, other features of enteropathy (e.g. gluten), blood loss, iron deficiency, protein loss, eosinophilic gastroenteritis

Anaphylaxis, serous otitis, eczema, urticaria, angioedema, asthma, joint pains, migraine

\section{Table 2. Causes of food intolerance}

Cause

Enzyme defects

Pharmacological

Toxic effects

Allergy

Miscellaneous
Example

Alactasia

Intolerance to caffeine

Monosodium glutamate

Egg-induced asthma

Peptic ulcer, gall bladder disease, steatorrhoea (various causes), irritable bowel syndrome (some cases) 
toxic symptoms can occur in up to $40 \%$ of the population. These deficiencies are not confined to particular ethnic groups. Less severe enzyme deficiencies of the same type may go unrecognized in Europe, and drugs which interfere with the metabolism of substances ranging from alcohol (antabuse) to histamine (isoniazid) (Uragoda \& Kottegoda, 1977) can add an iatrogenic element to these food-intolerant conditions.

The assumption that the food is itself the cause of symptoms is not always justified. The ingestion of unwashed fruit coated with weedkiller sprays can mimic food intolerance, in this case by suppression of the enzyme pathways which are dependent on cholinesterase (EC 3.1.1.8) (Ratner et al. 1983).

\section{Pharmacological and pseudo-allergic effects}

Nausea, vomiting and abdominal pain are among the symptoms which are reported by patients who have an excessive consumption of tea or coffee. Much more common, however, are the symptoms of tachycardia, insomnia, nervousness and tremor or 'restless legs', as described by Finn \& Cohen ( 1978 ) and Finn (r g82). There is general agreement that these symptoms are not due to true allergy but to a high intake resulting in a form of caffeine poisoning. Some pharmacological effects can, however, occur with a relatively low intake of the substance concerned. It is possible that reactions to many food additives come into this category, since there is often no evidence of an immunological cause.

When aspirin causes adverse effects, the subjects affected are sometimes atopic individuals who have high $\operatorname{IgE}$ levels and evidence of other allergies. This is by no means invariable, and there are often features which suggest a different mechanism: the association with nasal polyps (Spector \& Farr, 1983); the fact that tolerance can be induced within a few hours and disappear almost as quickly (Stevenson $e t$ al. I980); and the fact that unrelated cyclo-oxygenase-inhibiting drugs usually cause identical effects in susceptible subjects. Non-atopic aspirin-sensitive individuals may, nevertheless, have many clinical features which suggest allergy, including intolerance to a number of foods which do not necessarily contain salicylates (Asad et al. I 983). Furthermore, they not infrequently develop asthma or urticaria after an aspirin challenge, suggesting the same type of mediator release or the same end organ effects as those which accompany the allergic process. While food-intolerant patients who present with asthma or eczema usually do have other evidence of an IgE-mediated response (Lessof et al. 1980), it should now be accepted that 'pseudo-allergic' triggering of the inflammatory pathways can also occur (Moneret-Vautrin, 1983 as in drug idiosyncrasies (Schlumberger, 1980). While the mechanism remains to be clarified, aspirin-sensitive individuals have been found to have abnormalities of prostaglandin metabolism which may be relevant not only to their sensitivity to cyclo-oxygenase-inhibiting drugs but also to the food-intolerant symptoms which many of them display (Asad et al. 1984 ).

\section{Toxic effects}

It is difficult to distinguish between intolerance caused by an individual susceptibility and the toxic effects of a universal poison. Nevertheless, only the 
reactions of the susceptible individual come within the remit of the present paper. Reactions to food additives such as monosodium glutamate (Kwok, 1968) are sometimes regarded as the simple toxic effects of as much as $5 \mathrm{~g}$ glutamate, together with the large amount of sodium which may be present in a Chinese meal. Nevertheless, there is considerable variation in an individual's susceptibility to the oesophagitis and other clinical effects which this substance can initiate. The cause of this variation is unknown. In other instances the variation in susceptibility to toxic substances is beginning to be understood. The red suya syndrome of haemolytic anaemia and disturbed liver function tests is known to be caused by orange-RN dye, used as a food additive. This syndrome has been a particular problem in Nigeria, where it has been shown that glucose-6-phosphate dehydrogenase ( $E C$ I.I.1.49) deficiency is a predisposing factor (Okinyanju \& Odusote, 1983).

\section{Food allergy}

With the increasing recognition of other types of food intolerance, true allergic reactions to foods have come to be seen in better perspective. In the 'immediate' type of allergic reaction, foods containing milk, egg, fish, nuts, yeast and some meat products often provoke symptoms within an hour and it is in such cases that an association with asthma, eczema and urticaria is most likely and $\operatorname{IgE}$ antibodies to the food are most often found (Lessof et al. 1980). The symptoms vary, but it has been noted that patients who have suggestive evidence of specific food intolerance in association with the irritable bowel syndrome seldom have abnormal IgE levels or other evidence of an immunological abnormality (Alun Jones et al. 1982). The few who do are thought to be distinguishable on clinical grounds because of a clear association with other features such as asthma or eczema, as evidence that the reaction is not confined to the gastrointestinal tract (Pearson et al. 1983).

In some cases, there is evidence of a different type of immunological abnormality-which does not involve IgE-as in gluten enteropathy or the childhood enteropathies caused by cow's milk protein or occasionally by chicken, soya-bean or other foods. In such cases the reaction appears to be non-immediate but, apart from small bowel biopsy, investigation methods provide little diagnostic information.

\section{Diet in diagnosis and management}

Where there are reasons to suspect a particular food or foods as the cause of a reaction, it is a relatively simple matter to eliminate the food concerned and subsequently, to arrange an open and, if appropriate, a blind challenge test. Where there is some doubt as to which food should be eliminated, it is necessary to use an arbitrarily restricted diet which excludes those foods which are chiefly suspect. In those with symptoms suggestive of allergy, the foods which are usually eliminated are milk products, egg, fish, nuts, all meat apart from lamb or mutton, and also wheat and gluten, alcohol, citrus fruits, spices and food additives. In those who 
have symptoms of the irritable bowel syndrome, it has been suggested that the elimination diet can be modified to allow for the fact that meat and fish are rarely the cause of symptoms but potato may be (Alun Jones et al. 1982). A number of variations on the dietary theme are possible, but only in exceptional circumstances is a more severely restricted diet required. If the symptoms do not resolve after $2-3$ weeks of the dietary approach, other causes for the patient's illness should be sought.

If the symptoms do indeed remit, the rest of the diagnostic process may be difficult, especially if allergy tests are negative. This is because challenge tests do not always provoke a clinical reaction, even in those who are sensitive. It has been shown that the clinical response can depend on such variables as the amount of exercise taken (Maulitz et al. 1979). Methods for detecting subclinical reactions have therefore aroused interest. It has been shown that there is a release of prostaglandins which coincides with gastrointestinal reactions (Buisseret et al. 1978; Rask-Madsen \& Bukjave, 1979; Alun Jones et al. 1982). The detection of prostaglandins and other mediators may thus help in the analysis of the mechanism involved and may also help to identify subclinical reactions. Exceptionally, histamine and serotonin measurements have been used as indicators of an adverse response (Heatley et al. 1982; Little et al. 1983), and food-induced changes can also be detected indirectly by demonstrating a change in the threshold to non-specific stimuli. As yet, this latter approach has only been applied when the target organ is the lung, i.e. in patients with a history of asthma induced by cola drinks who, after an appropriate food challenge, were shown to have an increased sensitivity to inhaled histamine (Wilson et al. I982). It will be of interest to see whether a similar principle can be applied to other types of clinical sensitivity.

It is exceptional to require the long-term elimination of a wide range of foods but this may occasionally be needed, for example in highly allergic subjects with severe asthma. The help of a skilled dietician is essential in such cases in order to avoid the problems of inadequate nutrition or deficiencies of calcium and vitamins. Where the symptoms are due to non-immunological causes, it is often found that occasional dietary indiscretions are well tolerated, provided that they are not repeated on successive days. Even in true food allergy, there is a tendency to remission after a period of dietary restriction, for example in infants with cow's milk protein intolerance, whose intolerance sometimes disappears within 6 months (Bahna \& Heiner, 1980 ). With this in mind, numerous desensitizing techniques have been used, and some of these have been given considerable publicity. It should be emphasized that there is as yet no controlled trial evidence that any of these techniques produce results which are better than placebo.

\section{REFERENCES}

Alun Jones, V., McLaughlin, P., Shorthouse, M., Workman, E. \& Hunter, J. O. (I982). Lancet ii, I 15. Asad, S. I. Kemeny, D. M. Youlten, L. J. F., Frankland, A. W. \& Lessof, M. H. (1984). British Medical fournal 288, 745-748.

Asad, S. I., Youlton, L. J. F. \& Lessof, M. H. (1983). Clinical Allergy 1 3, 459- 466.

Bahna, S. L. \& Heiner, D. C. (1980). Allergies to milk. New York: Grune and Stratton.

Buisseret, P. D., Youlten, L. J. F., Heinzelmann, D. I. \& Lessof, M. H. (1978). Lancet i, 906-908. 
Finn, R. (1982). In Clinics in Immunology and Allergy, vol. 2, no. I Food Alergy, pp. I65-203 [J. Brostoff and S. J. Challacombe, editors]. London: W. B. Saunders.

Finn, R. \& Cohen, N. H. (1978). Lancet i, 426-428.

Heatley, R. V., Denburg, J. A. \& Bayer, N. (1982). Clinical Allergy 1 2, 1 49-1 59.

Kwok, R. H. M. (1968). New England Fournal of Medicine $278 \mathrm{~m}, 796$.

Lessof, M. H. (editor) ( 1983 ). In Clinical Reactions to Food, pp. 102-1 33. Chichester: John Wiley \& Sons.

Lessof, M. H., Wraith, D. G. \& Merrett, T. G. (1980). Quarterly fournal of Medicine 195, 259-27I.

Little, C. H., Steaart, A. G. \& Fennessy, M. R. (1983). Lancet ii, 297-299.

Maulitz, R. M., Pratt, D. S. \& Schockett, A. L. (1979). Fournal of Allergy and Clinical Immunology 63, 433-434.

Moneret-Vautrin, D. A. (1983). In Clinical Reactions to Food, pp. I 35-I 54 [M. H. Lessof, editor]. Chichester: John Wiley \& Sons.

Okinyanju, O. O. \& Odusote, K. A. (I983). Lancet ii, I 3 I 4 .

Pearson, D. J., Rix, K. J. B. \& Bentley, S. J. (1983). Lancet i, 1259-1261.

Rask-Madsen, J. \& Bukjave, K. (1979). Scandinavian fournal of Gastroenterology 14 (Supplement 53), 73-78.

Ratner, D., Oren, B. \& Vigder, K. (1983). Israel Yournal of Medical Sciences I9, 810-814.

Schlumberger, H. D. (1980). In Pseudo-allergic Reactions, pp. I $25^{-20} 3$ [P. Dukor, editor]. Basel: Karger.

Spector, S. L. \& Farr, R. S. (1983). In Allergy: Principles and Practice, 2nd ed., pp. 1249-1273 [E. Middleton, C. G. Reed and E. F. Ellis, editors]. St Louis: C. F. Mosby.

Stevenson, D. D., Simon, R. A. \& Mathison, D. A. (1980). Fournal of Allergy and Clinical Immunology 66, 82-88.

Uragoda, C. G. \& Kottegoda, S. R. (1977). Tubercle 58, 83-89.

Wilson, N., Vickers, H. \& Taylor, G. (1982). British Medical fournal 284, 1 226-1 228. 